\title{
Perspective taking, pictures, and the blind
}

\author{
MORTON A. HELLER \\ Winston-Salem State University, Winston-Salem, North Carolina \\ and \\ JOHN M. KENNEDY \\ University of Toronto, Toronto, Ontario, Canada
}

\begin{abstract}
Congenitally blind, late blind, and blindfolded sighted controls attempted a Piagetian perspectivetaking (three-mountain) task. Piaget used the term perspective to mean point of view (Piaget \& Inhelder, 1967, p. 210), and the present usage does not imply linear perspective. Subjects used raised-line drawings to depict alternative points of view of an array of three geometric solid forms (cube, cone, and ball). They then identified the point of view of raised-line drawings. The effect of visual status on accuracy was nonsignificant for both response measures. Using alternating vision of the array and drawings, sighted subjects in a control condition performed like the congenitally blind. However, congenitally blind individuals did require more time than the other subjects for the perspective-taking task. In an additional experiment, no difference was found between the three groups in the accuracy or speed of tactile shape matching. The results suggest that visual imagery and visual experience are not necessary for tactile perspective taking.
\end{abstract}

Research on spatial cognition in the blind has been, and still is, fraught with controversy. Von Senden proposed that vision is the only proper sense for the understanding of space, whereas Berkeley claimed that touch educates vision in depth relationships (see Juurmaa, 1973, p. 92). Few psychologists have followed Berkeley's lead after the emergence of a large literature on intersensory discrepancy (Heller, 1983; Welch \& Warren, 1980). The most prevalent view has been that vision is the "best" sense for the understanding of spatial relations. Vision tells us about form more rapidly than touch (Davidson, Abbott, \& Gershenfeld, 1974; Heller, 1984), and it is usually more accurate than touch when forms are twodimensional and time is limited (Loomis, 1981). Furthermore, vision is dominant over haptics for shape detection when the two senses are in conflict and vision is clear and foveal (Rock \& Victor, 1964). Touch may be relied

Preparation of this report and some of the research were supported by NIH MBRS Grant 2SO6-08040 to M. A. Heller. We wish to thank Kimberly D. Nesbitt and Kelly Gibbs for aid in data collection and statistical analyses, Carl Perry for valuable aid with statistics and in drawing Figure 1, and Faith Heller and two anonymous reviewers for helpful comments on an earlier version of the manuscript. We are grateful to the participants and to the staff and administrators at the Industries for the Blind Workshops in Greensboro and Winston-Salem, including: Sandra Coon, Laura Spain, Delmer Wall, Derek Davis, and Linda Wade. We thank the Ontario Science Centre for assistance in this study. We wish to thank Emerson Foulke for the loan of a special slate that was used to emboss the forms used in Experiment 1. Address reprint requests to Morton A. Heller, Psychology, Winston-Salem State University, Winston-Salem, NC 27110 , or to John Kennedy, Department of Psychology, Scarborough Campus, University of Toronto, Scarborough, Ontario M1C 1A4, Canada. upon, however, when vision is blurred (Heller, 1983) or for judgments of surface texture (Heller, 1982, 1989c; Lederman, Thorne, \& Jones, 1986).

The emphasis on the superiority of visual spatial cognition has led some researchers to believe that the blind must be deficient in their apprehension of space. This follows if one assumes that visual experience is necessary for spatial understanding. Bower (1977) apparently believed that the congenitally blind individual never develops an understanding of topological sequential spatial relations "such as on, in, behind, and in front of and between" (p. 160). Kinsbourne and Lempert (1980) went so far as to claim that the sense of touch cannot replace visual experience in spatial representation.

Visual experience may aid individuals in a number of ways. Vision may allow for a better and more rapid understanding of external spatial coordinate systems (see Millar, 1981; Warren, 1984). Sight may also permit the generation of visual images, which could aid the late blind (Worchel, 1951). They presumably remember how things "look." Jones (1975) has argued that a history of movement deprivation in blind individuals may limit their understanding of space. This is especially likely if blind children are overprotected by their parents or if they live in restrictive institutional environments. Pick (1974) has suggested that the sighted normally recode tactual impressions into visual images when touching forms (see Revesz, 1950). Visual imagery may help one remember complex sequences of familiar stimuli (Heller, 1989b). However, Kennedy and his associates have shown that blind people can understand raised-line pictures, and show a basic understanding of space in their drawings (Kennedy, 1983; Kennedy \& Domander, 1984; Kennedy \& Fox, 1977; Kennedy \& Gabias, 1985). 
More recent research has shown that the sighted may have no advantage over the congenitally blind in relative smoothness judgments (Heller, 1989c), tactile shape matching, or identification of some tactile pictures (Heller, 1989a). The late blind performed far better than the sighted or congenitally blind in naming raised-line drawings via the sense of touch. Heller (1989a) suggested that the advantage of the late blind accrued from an appreciation of the rules governing the translation of threedimensional objects into a two-dimensional format (see Millar, 1975). The late blind may also have better tactile skills than the sighted.

According to Millar (1988) and Dodds, Howarth, and Carter (1982) blind children tend to code egocentrically, in terms of a body-centered frame of reference. Dodds et al. (1982) found that most of the 11-year-old congenitally blind children in their study coded space in terms of self-reference, whereas the late blind tended to represent space in terms of externally referent maps. One of the congenitally blind observers in the Dodds et al. experiment was able to go beyond egocentrism in representing space. This suggests that there may simply be a developmental lag when one is forced to rely on touch, and congenitally blind individuals may eventually develop a higher level of spatial understanding (see Millar, 1988; Piaget \& Inhelder, 1948/1967).

The following experiments were designed for the purpose of studying the impact of visual experience on spatial cognition. On the view that vision is essential for an understanding of space, one would expect lower performance on tactile form perception tasks in the congenitally blind. Alternatively, one might expect better performance in these tasks by the blind, because of their greater familiarity with tactual-spatial patterns such as braille and increased experience with the use of the skin for shape detection. Yet a third possibility is that blind people will be superior to the sighted on two-dimensional patterns but inferior on two-dimensional pictures of three-dimensional space. In the first experiment, sighted, late blind, and congenitally blind individuals engaged in a shape matching task that served as a baseline measure of tactile skills.
The second experiment entailed a special variant of Piaget's three-mountain, perspective-taking task (Piaget \& Inhelder, 1948/1967; Simpkins, 1979). Piaget claimed that young children are egocentric and are unable to take the point of view of another person. However, research has shown that, in some tasks, rather young sighted children are capable of recognizing the existence of an external viewpoint and engaging in role-taking (Borke, 1975). The term perspective taking refers to the ability of an individual to understand the viewpoint of another person; it does not necessarily imply linear perspective. The same three groups (as in Experiment 1) of early blind, late blind, and blindfolded sighted subjects were exposed to an array of three solid geometric objects. They were then asked to draw a top "view" and side "views" of the array from a number of imagined vantage points, using a raised-line drawing kit. Subsequently, the subjects were exposed to tactile drawings indicating the various vantage points and asked to identify the perspective (i.e., viewpoint) of the picture.

If vantage points and perspective taking were specifically visual and not known to the congenitally blind, one might expect that the early blind would all fail at the perspective-taking task. If the blind tend toward egocentrism (see Dodds et al., 1982; Millar, 1988), but are capable of taking the point of view of another person, one still might expect superior performance in the sighted and late blind. Alternatively, an amodal view of spatial cognition would predict no difference between the sighted and blind in perspective taking (Kennedy, 1982; see Strelow, 1985, for further discussion of this issue). One might even expect a superiority for the blind over the sighted if it is initially disorienting to be denied sight with a blindfold (see Heller, 1982, 1985).

\section{EXPERIMENT 1}

\section{Shape Matching}

Although our chief interest lies in vantage-point tasks, we need to show that embossed two-dimensional patterns are equally legible to all groups. Sighted, congenitally

Table 1

Characteristics of the Blind Subjects, Including Age, Education, Cause, and Presence of Light Perception

\begin{tabular}{|c|c|c|c|c|c|c|c|c|c|}
\hline \multicolumn{5}{|c|}{ Early Blind } & \multicolumn{5}{|c|}{ Late Blind } \\
\hline Sex & Age & LP? & Cause & Education & Sex & Age & LP? & Cause & Education \\
\hline $\mathbf{M}$ & 26 & yes & optic nerve & high school & $\bar{M}$ & 24 & no & detached retinas (13) & high school \\
\hline $\mathbf{F}$ & 33 & no & RLF & some college & $\mathbf{F}$ & 32 & yes & RP (15) & high school \\
\hline $\mathbf{M}$ & 34 & yes & optic nerve & college graduate & $\mathbf{M}$ & 35 & no & RP (30) & some college \\
\hline $\mathbf{M}$ & 35 & yes & RLF & college graduate & $\mathbf{M}$ & 38 & yes & optic glioma (21) & high school \\
\hline $\mathbf{F}$ & 36 & yes & RLF & some college & $\mathbf{F}$ & 41 & yes & RP (18) & high school \\
\hline $\mathbf{F}$ & 50 & no & born without eyes & high school & $\mathbf{M}$ & 42 & no & glaucoma (8) & high school \\
\hline $\mathbf{M}$ & 51 & no & glaucoma & high school & $\mathbf{M}$ & 49 & no & trauma $(31)$ & Grade 8 \\
\hline $\mathbf{M}$ & 52 & no & glaucoma & high school & $\mathbf{M}$ & 49 & yes & glaucoma (11) & high school \\
\hline F & 52 & yes & $\begin{array}{l}\text { RP, congenital } \\
\text { nystagmus and } \\
\text { kerataconus }\end{array}$ & high school & $\mathbf{M}$ & 53 & no & trauma $(32)$ & Grade 10 \\
\hline
\end{tabular}

Note-Most of the early blind (7) attended schools for the blind. The majority of the late blind (6) attended the general public schools. In addition, many blind subjects attended rehabilitation programs after finishing high school. LP = light perception. RP $=$ retinitis pigmentosa. RLF $=$ retrolental fibroplasia. Age at complete loss of vision is shown in parentheses. 
blind, and late blind subjects made bimanual, tactualtactual $(T-T)$ matches of embossed patterns. Bimanual matches were used to increase task difficulty, since prior research with one-handed matching showed no difference in matching accuracy between groups of sighted and blind observers (see Heller, 1989a).

\section{Method}

Subjects. There were 27 subjects in the present experiments. The characteristics of the blind subjects can be seen in Table 1. All subjects participated in both experiments. None of the blind individuals had more than minimal light perception; none could see hand movements or form. All of the congenitally blind (CB) subjects were blind from birth, with the exception of 2 subjects who had some vision prior to 3 months of age. The CB female subject with retinitis pigmentosa claimed she had never seen, and was educated in schools for the blind (this person was also diagnosed with congenital nystagmus and kerataconus). The CB individuals with retrolental fibroplasia (RLF) were blind when removed from incubators. RLF is produced by excessive administration of oxygen to premature infants. None of the blind subjects in the present experiments had any known additional deficits. ${ }^{1}$ Prematurity can sometimes be associated with neurological problems and spatial disorders, but the RLF subjects in the present experiments functioned "normally." The mean ages of the CB, late blind (LB), and sighted controls were $41,40.3$, and 37.6 , respectively. The blind subjects were recruited at Industries of the Blind workshops in Winston-Salem and Greensboro; the sighted (tactile) controls were recruited on an undergraduate campus in Winston-Salem (4 women and $5 \mathrm{men}$ ). The subjects in the visual conditions described in Experitnent 2 were adults recruited at the Ontario Science Centre in Toronto. ${ }^{2}$ All subjects first engaged in shape matching and then attempted the perspective task.

Stimuli and Apparatus. The $12.5-\mathrm{mm}$ square stimcii consisted of eight simple patterns embossed with a $6 \times 6$ array of dots. These dots, which had the same size as that of the dots in normal braille, were produced with a special slate and a braille stylus on a plastic braille card. Interdot spacing was also similar to that of braille (see Figure 1). The eight stimuli were presented three times each in a random sequence. They were arranged in four horizontal rows with six shapes in each. Interstimulus spacing was approximately $1 \mathrm{~cm}$, with about $1.5 \mathrm{~cm}$ between each horizontal line. The matching stimulus array consisted of the eight stimuli in a horizontal line about $5 \mathrm{~cm}$ above the lines of standard stimuli. Sighted subjects were unable to see the stimuli because they were behind a Masonite screen with a cloth-covered opening at its base. The stimuli were mounted on a foam-covered horizontal shelf.

Design and Procedure. The design was a simple one-way analysis of variance, with independent groups representing visual status (sighted, $\mathrm{LB}$, and $\mathrm{CB}$ ). The subjects examined the standard stimuli with one index finger while they explored the matching array with the other. About half the subjects used the left index finger for the standards and half used the right. They explored the array of standards from left to right and indicated a match by tapping the appropriate choice form in the matching array. The subjects were timed on each line of shapes with a stopwatch, and feedback was not given.

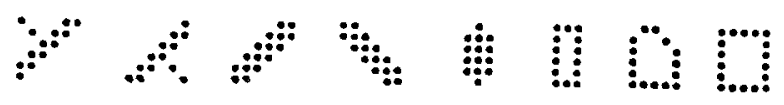

Figure 1. Stimuli used in Experiment 1: The shapes are drawn to scale, with a height of $12.5 \mathrm{~mm}$.
Table 2

Effect of Visual Status on Mean Number Correct and Mean Time Per Item (in Seconds) in Tactual-Tactual Bimanual Shape Matching

\begin{tabular}{|c|c|c|c|c|c|}
\hline \multirow[b]{2}{*}{ Visual Status } & \multicolumn{2}{|c|}{$\begin{array}{l}\text { Number } \\
\text { Correct }\end{array}$} & \multirow{2}{*}{$\begin{array}{c}\text { Mean \% } \\
\text { Correct }\end{array}$} & \multicolumn{2}{|c|}{$\begin{array}{l}\text { Mean } \\
\text { Time }\end{array}$} \\
\hline & $M$ & $S D$ & & $M$ & $S D$ \\
\hline Sighted & 15.1 & 3.8 & 62.9 & $19 . \overline{7}$ & 6.8 \\
\hline Congenitally blind & 18.9 & 4.1 & 78.8 & 14.2 & 9.9 \\
\hline Late blind & 18.7 & 4.2 & 77.9 & 15.3 & 12.4 \\
\hline
\end{tabular}

\section{Results and Discussion}

Table 2 shows similar performance for the three groups of subjects. The effect of visual status was nonsignificant for number correct $[F(2,26)=2.48, p>.05]$ and for mean exploration time per item $(F<1)$. Although the blind subjects were somewhat faster and more accurate than the sighted, the effect of visual status was minimal with bimanual matches. Thus the subjects were comparable on a flat, tactual form perception task. They were therefore appropriate for comparison in a tactile perspectives picture task. These results are inconsistent with the idea that visual imagery and visual experience are necessary for tactual form perception.

\section{EXPERIMENT 2}

\section{Perspective Taking}

The subjects were haptically exposed to a threedimensional array that consisted of a cube, cone, and sphere. They were told to draw views of the array from a number of different vantage points with a raised-line drawing kit. Subsequently, they were shown pictures drawn from various points of view, and asked to identify the vantage point of the picture. There were a number of reasons for predicting low performance for the congenitally blind. The visual experience and visual imagery position would lead one to expect that haptics should yield an inferior understanding of space. Thus, the congenitally blind should be least likely to develop an "objective" understanding of space. Furthermore, the congenitally blind have had minimal experience with drawing and this may impair performance. However, an amodal interpretation of spatial cognition would lead to the prediction of no difference between the groups.

\section{Method}

Subjects. The subjects were the same as in Experiment 1. Most of the blind subjects had served in a prior study by the first author in picture perception (Heller, 1989a); 2 of the CB subjects and 4 of the LB subjects in that study did not participate in Experiments 1 and 2 . In most instances, these subjects could not participate because they had moved to a distant location (but one person was ill). The subjects had performed at an above-average level in the earlier picture perception research.

Stimuli and Apparatus. The three-dimensional array consisted of a cube $(8.9 \mathrm{~cm}$ square), cone $(8.9-\mathrm{cm}$-diameter base $\times 8 \mathrm{~cm}$ high), and sphere $(8.9 \mathrm{~cm})$. Figure 2 shows a top view of the spatial array as mounted on foam board (about $29.5 \times 42 \mathrm{~cm}$ ). The separation between the cube and cone (nearest edges) was about $5.6 \mathrm{~cm}$, there were approximately $14.5 \mathrm{~cm}$ between the cube and sphere, 


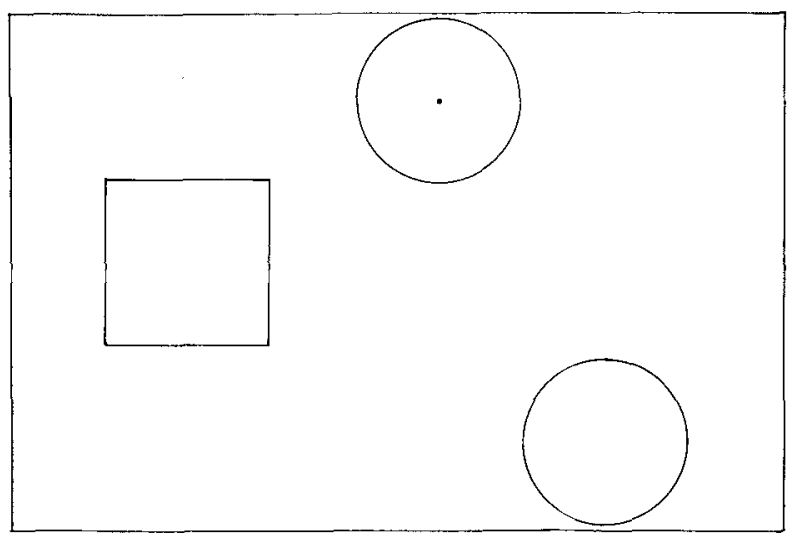

Figure 2. Top view of the three shapes used in the perspectivetaking task: The 8.9-cm shapes are drawn to scale; the $X$ indicates the position of the subjects.

and the cone and sphere were $11.6 \mathrm{~cm}$ apart. The subjects used a Swedish raised-line drawing kit obtained from the Swedish Foundation for the Blind (RPH-SYN). The kit allows one to produce raised-line drawings by pressing a pen into a textured, plastic "paper" covering on a rubber-surfaced board. The "paper" was in two sizes, small (about $20.5 \times 30.5 \mathrm{~cm}$ ) and large $(30 \times 43 \mathrm{~cm})$. The larger paper was used for life-sized drawings. Sighted haptic controls were blindfolded throughout.

Procedure. The subjects first haptically examined the objects in the array; they were told to name the shapes, and then they were asked to draw top and side views on small writing paper. They first drew a top view of each three-dimensional shape and then a side view. It should be noted that many of the sighted, as well as the blind subjects, used "incorrect" names for the objects. For example, a number of persons called the sphere a circle or an apple, the cone was called a funnel, and the cube was called a square or a box. When a subject seemed unclear about what the instruction to draw "a side or top (or bird's eye) view" meant, the experimenter placed the subject's hand on the side or top of the shape. In addition, the subjects were instructed to draw side views on a line drawing of a table top, and were told to imagine "looking" at the table top with their perceptual organ at that level. Subsequently, the subjects were shown raised-line pictures of the three shapes, each drawn as a side view (with a table top drawn for clarity) and a top view. They were told to identify the shape and point of view of each of the six pictures, with feedback. This procedure was followed to ensure that the subjects knew what it meant to represent stimuli from differing points of view.

The subjects were next asked to draw a life-sized top view of the array of three objects, maintaining true distance relations on the board. They were told that the drawing paper was the same size as the board that the stimuli were mounted on. No time limit was imposed; the subjects repeatedly examined the objects and their drawings in progress. It should be noted that it was not possible for subjects to feel the three-dimensional shape while drawing, since they needed their other hand to keep the paper in place, to keep track of starting and endpoints while drawing, and so forth. Thus, the subjects in this haptic drawing task could feel the array or feel their drawings, but not do both simultaneously. The drawing material was placed in front of the three-dimensional array, not off to one side. They were allowed to reexamine the array as often as they wished. They were not permitted, however, to change their position with respect to the array, nor were they allowed to move the array. Only 1 (CB) subject attempted to maneuver his arm to approach the object array from that perspective, and so a "motor theory" cannot account for the data. Furthermore, this sort of maneuver was not possible for the $180^{\circ}$ perspective. The subjects were then asked to draw a reduced (to scale) drawing on the small paper. This was done to try to ensure adequate familiarity with the spatial configuration. Subsequently, the subjects were asked to draw side views of the array from their own point of view, and as it would look to a person sitting on the right $\left(+90^{\circ}\right)$, to someone sitting across from (opposite) them $\left(+180^{\circ}\right)$, and to the experimenter, who was on the left $\left(+270^{\circ}\right)$. Before making the drawings of the side views, the subjects were told to think as follows: "What would be on the left for someone sitting there? What would that person see in the middle? What would that person see on the right?"' These drawings were made on the small paper, on predrawn lines representing table tops. The subjects vocally named the shapes as they drew them.

After having completed the drawing task, the subjects were shown life-sized drawings of the array from the top, or side views drawn from the front, right $\left(+90^{\circ}\right)$, opposite $\left(+180^{\circ}\right)$, or left $\left(+270^{\circ}\right)$. The five drawings were shown twice each in a random arrangement, for a total of 10 perspective identification trials with pictures (see Figure 3). The subjects were permitted to use two hands for haptic exploration, but they were not given any time limits, with either drawing or pictures. The perspective identification task required the subjects to name both the viewpoint of the drawing (top or side) and the point of view of the perceiver (e.g., front view, opposite, etc.) for a correct score. No feedback was given while the subjects were drawing perspectives or during the picture/perspective identification task. It should be pointed out that the subjects did not wish to reexamine the three-dimensional array during the picture identification phase, since they were convinced that they understood the spatial layout.

\section{Results and Discussion}

We obtained two indices of the subjects' understanding of perspective taking: the drawings and the picture identification task. Performance in the identification task will be described first. The congenitally blind were able to identify the point of view represented in the 10 raisedline drawings. The mean number of correct identifications for the CB, LB, and sighted subjects were $6.7(S D=2.4)$, $8.3(S D=1.8)$, and $7.4(S D=2.7)$, respectively. The effect of visual status was nonsignificant $[F(2,24)=1.2$, $p>.05$ ]. All groups were significantly different from chance (where chance is 2 in 10 ).

The subjects' drawings were examined to determine the number of correct productions, which was based on the shapes' being drawn in the correct sequence. In addition, scoring the top view drawing correct required that subjects place the stimuli in the correct sequence from both the front and the side. The drawing score reflects performance on the life-sized top view, and the four drawings

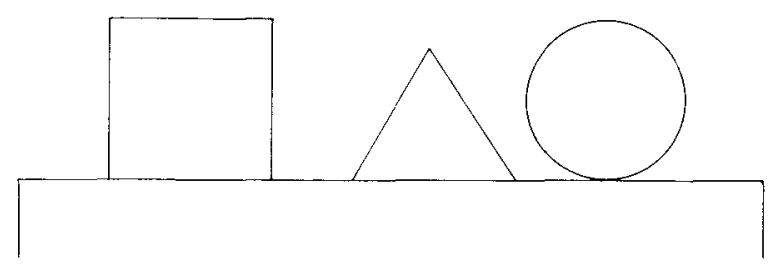

Figure 3. Frontal, side view of the array. 
Table 3

Effect of Visual Status on Frequency of Correct Drawings and Identifications at Each Perspective

\begin{tabular}{|c|c|c|c|c|c|c|c|c|c|c|c|c|}
\hline \multirow[b]{3}{*}{ Visual Status } & \multirow[b]{3}{*}{$n$} & \multicolumn{10}{|c|}{ Viewpoint } & \multirow{3}{*}{$\begin{array}{c}\text { Total } \\
\text { Mean } \\
\text { No. } \\
\text { Correct }\end{array}$} \\
\hline & & \multicolumn{2}{|c|}{ Top } & \multicolumn{2}{|c|}{ Front } & \multicolumn{2}{|c|}{ Right $\left(+90^{\circ}\right)$} & \multicolumn{2}{|c|}{$+180^{\circ}$} & \multicolumn{2}{|c|}{ Left $\left(+270^{\circ}\right)$} & \\
\hline & & Freq. & $\%$ & Freq. & $\%$ & Freq. & $\%$ & Freq. & $\%$ & Freq. & $\%$ & \\
\hline \multicolumn{13}{|c|}{ Drawing Task } \\
\hline Sighted visual & 11 & 11 & 100 & 11 & 100 & 4 & 36.4 & 7 & 63.6 & 5 & 45.5 & 3.45 \\
\hline Sighted haptic & 9 & 8 & 88.9 & 9 & 100 & 4 & 44.4 & 8 & 88.9 & 6 & 66.7 & 3.9 \\
\hline Congenitally blind & 9 & 7 & 77.8 & 9 & 100 & 5 & 55.6 & 5 & 55.6 & 5 & 55.6 & 3.44 \\
\hline Late blind & 9 & 7 & 77.8 & 9 & 100 & 6 & 66.7 & 8 & 88.9 & 8 & 88.9 & 4.22 \\
\hline \multicolumn{13}{|c|}{ Identification Task } \\
\hline Sighted visual & 11 & 19 & 86.4 & 18 & 81.8 & 16 & 72.7 & 19 & 86.4 & 11 & 50.0 & 7.5 \\
\hline Sighted haptic & 9 & 14 & 77.8 & 14 & 77.8 & 13 & 72.2 & 12 & 66.7 & 14 & 77.8 & 7.4 \\
\hline Congenitally blind & 9 & 18 & 100 & 15 & 83.3 & 13 & 72.2 & 7 & 38.9 & 7 & 38.9 & 6.7 \\
\hline Late blind & 9 & 16 & 88.9 & 15 & 83.3 & 14 & 77.8 & 13 & 72.2 & 17 & 94.4 & 8.3 \\
\hline
\end{tabular}

Note-The 11 subjects in the sighted visual conditions were tested at the Ontario Science Centre; the other subjects were tested in North Carolina. The maximum frequency possible for drawings $=9$ for the haptic conditions and 11 for the visual; for identification $=18$ for the haptic conditions and 22 for the visual. Maximum number correct $=5$ for drawing and 10 in identification task.

of side views. The mean number of correct drawings (out of 5) for the congenitally blind, late blind, and sighted were $3.44(S D=1.5), 4.22(S D=1.1)$, and 3.89 $(S D=1.4)$, respectively. The effect of visual status was not significant $(F<1)$. A second analysis that yielded identical results was performed on number correct, but excluded the top view. Since there were three objects and six orders in which they could be drawn left to right, a chance score was 1 in 6 (less if location is considered in addition to order in the top view). All groups of subjects performed at a level greater than chance. These results suggest that the congenitally blind are certainly able to understand the point of view of another person, and can effectively represent these viewpoints with raised line drawings.

One might expect that the subjects differed in their ability to place the drawings accurately on the picture surface. Thus, some researchers might assume that tactile drawings may be too difficult to interpret, and this may have lowered the performance of the blindfolded sighted or blind. Consequently, a group of 11 subjects attempted the perspective-taking task using vision, with the same stimuli as had been used for haptic conditions. These sighted observers (mean age $=45.3$ ) drew with a paper and pencil. They were allowed to see the array and their drawings, but they were not permitted to see the array while they were actually drawing. This was done to make conditions as much like the haptic procedure as possible. The visual subjects were able to request sight of the ar-

Table 4

Effect of Visual Status on Mean Absolute Displacement Errors (in Centimeters) in Locating Three Shapes (Top View)

\begin{tabular}{|c|c|c|c|c|c|c|}
\hline \multirow[b]{3}{*}{ Visual Status } & \multicolumn{6}{|c|}{ Shape } \\
\hline & \multicolumn{2}{|c|}{ Cube } & \multicolumn{2}{|c|}{ Cone } & \multicolumn{2}{|c|}{ Sphere } \\
\hline & $M$ & $S D$ & $M$ & $\overline{S D}$ & $M$ & $S D$ \\
\hline Congenitally blind & 4.6 & 2.5 & 3.8 & 3.3 & 3.3 & 2.4 \\
\hline Late blind & 3.8 & 2.2 & 3.7 & 4.3 & 5.4 & 5.0 \\
\hline Sighted & 5.2 & 2.9 & 6.3 & 5.2 & 4.4 & 1.5 \\
\hline
\end{tabular}

ray upon demand; the array was covered while the subjects were actually drawing. In addition, a screen prevented the subjects from seeing their pictures while looking at the array. Thus, the subjects could draw or view the array, but they could not do both at the same time. In other ways, the procedure was like that for the haptic conditions. Performance in the visual condition was very much like that for sighted subjects in the haptic conditions (see Table 3). It was interesting that the congenitally blind subjects were able to do as well in the tactile drawing task as the sighted subjects using vision and making paper and pencil drawings. It should be pointed out that the late blind performed at a slightly higher level, and that their judgments were more consistent and less variable.

The preceding response measure was based on the individual's understanding of perspective, but it mainly reflected an understanding of sequential order. Consequently, one might assume that the congenitally blind know that things look different from alternative points of view, but that they do not really have a good "grasp" of the true spatial metric. We did not obtain life-sized drawings from different points of view, but we did have that information for the top view. We therefore undertook a number of detailed measurements of the life-sized (top view) drawings.

The displacement errors of the congenitally blind subjects were somewhat smaller than those of the sighted subjects restricted to touch. Table 4 shows mean errors in correct placement of the drawings of the three shapes. The error scores in placement represent the mean error in centimeters that the midpoint of each drawn shape was displaced from the true midpoint in the three-dimensional array. An analysis of variance was performed on the error scores, with the factors being visual status (congenitally blind, late blind, and sighted controls) and shape (cube, cone, and sphere), with repeated measures on shape. The effects of visual status and shape were both nonsignificant (both $F \mathrm{~s}<1$ ) and the interaction was also nonsignificant $[F(4,48)=1.1, p>.05]$. These results 
are consistent with Hollins and Kelley's (1988) report that the blind showed good spatial understanding when placement was used as a response measure. ${ }^{3}$

\section{GENERAL DISCUSSION}

The results of these experiments show that the congenitally blind are able to take the point of view of another person. Visual experience does not appear to be necessary for perspective taking. These conclusions are supported by the results of Experiment 2. Furthermore, visual experience provided no benefit in simple tasks requiring tactual perception, such as bimanual shape matching (Experiment 1$).{ }^{4}$ The results are inconsistent with the notion that spatial representation requires visual imagery.

The present results, showing comparable performance in the blind and sighted in perspective taking, do not mean that there are no benefits to visual experience. The sighted and late blind took less time to complete the perspectivetaking drawing and identification tasks. Some of this time reduction may have derived from greater familiarity with drawing. However, the congenitally blind took significantly longer $(M=84 \mathrm{~min})$ than did the late blind $(M=41 \mathrm{~min})$ or the sighted $(M=39 \mathrm{~min})$ to complete all phases of the drawing and perspective identification tasks $[F(2,24)=20.4, p<.01]$. Performing a task slowly is certainly preferable to not being able to perform it at all. Many of the congenitally blind subjects seemed to take considerable time to build up a representation of space. Some of them paused to refer back repeatedly to the array in the midst of producing drawings. Others did not need to reexamine the array, and seemed to establish a representation (or mental image) of the spatial configuration quickly. Slower generation of a conception of a spatial configuration could present some difficulty in speeded tasks, such as mobility. The need for updating while exploring a large-scale environment could be problematic if time is of the essence (see Rieser, Guth, \& Hill, 1986). Given sufficient time, however, the congenitally blind are certainly capable of generating perspective representations by way of drawing. They also proved capable of interpreting the perspectives in drawings.

The results of the present experiments are not inconsistent with studies that show that visual experience aids spatial understanding, since blindfolded sighted individuals and the late blind may both perform better than the congenitally blind in some mobility tasks (Rieser et al., 1986; Strelow, 1985). We suggest that the early blind may run into difficulty when memory is heavily loaded and performance requires speed. Rieser et al. (1986) evaluated the ability of the blind to understand perspective structure in large-scale (room-sized) space. They examined their subjects' understanding of an array from a starting point and from vantage points to which the subjects walked; they also required subjects to imagine the array from alternative points of view. Rieser et al. told their subjects to point to the objects in the array from the new vantage point in both the imagination and the walk- ing conditions. They interpreted their results as showing strong support for the role of visual experience. Unlike the sighted and late blind, the early blind did not benefit from locomotion to new points of observation. Barber and Lederman (1988) also provided support for the influence of visual experience in a similar study involving a pointing response measure in small-scale space. Also, Hollins and Kelley (1988) reported that the blind make more errors than the sighted in pointing tasks. However, they also found that spatial skills were good in the blind when placement was used as a response measure in small-scale, manipulatory space. Thus, pointing may depend on spatial skills other than placement, and the blind person's skills may be underestimated in pointing tasks. Blind people, we have noticed, sometimes try to show the width and the direction of an object simultaneously while pointing. Sighted individuals may adhere solely to the notion of a straight line (see Piaget \& Inhelder, 1948/1967).

There were large individual differences among the blind subjects in both of the present experiments. Blind people are not homogeneous in their spatial abilities. Two of the congenitally blind individuals had perfect scores in the drawing measure of perspective taking, and one was also errorless in the identification task. At the other extreme, one of the congenitally blind persons was unable to perform the drawing perspective-taking task successfully and seemed unable to go beyond an egocentric point of view. We have noted this problem in pilot studies with sighted children aged 8-10, and in some of our sighted adults in the visual condition task of Experiment 2. Some of the blind subjects performed better on drawing than on picture identification. Thus the congenitally blind subjects did about as well as the sighted controis in drawing, but their identification scores were slightly lower for the $180^{\circ}$ and $270^{\circ}$ perspectives (see Table 3 ). It may have been difficult for some of these subjects to interpret tactile pictures while trying to generate an "image" of the array from different points of view. It should be pointed out too that sighted people also vary greatly in their spatial skills. Some are poor at map reading or perspective taking (Experiment 2). There are highly intelligent sighted individuals who have great difficulty in spatial reasoning, and some may have problems in drawing.

Since many of our sighted adults failed some aspect of the task, this perspective-taking task must be very difficult and demand a high level of spatial reasoning. Sighted individuals who made errors include ones with graduatelevel education in physics, economics, business, physiology, and psychology. The task requires one to coordinate knowledge of one's own position in space with a threedimensional array. Anticipating a different perspective forces the individuals simultaneously to consider the point of view of the self, the actual array, and a particular different representation-namely, the side view drawing from another perspective. In addition, subjects need to be able to manipulate their representations. For example, it is necessary to reverse a sequence to draw the $180^{\circ}$ perspective. The task requires one to be aware of all of the 
possible perspectives, and to decide which one is most appropriate for a given point of view. It should be noted that the difficulty of the perspective task cannot be ascribed to deficiencies in the haptic modality, because of similar performance of sighted subjects using vision (see Table 3). ${ }^{5}$

We should point out that the present experiments do not prove that sighted subjects never make use of visual imagery. It is plausible to suggest that visual imagery can aid the sighted to interpret tactual impressions. One might also argue that the sighted make use of visual imagery and that the blind have increased tactual skills. The two factors might "cancel each other out" and produce equivalent performance. However, visual imagery is clearly not necessary for the sort of spatial thinking measured by the perspective-taking task.

Haptic pictures represent useful devices for evaluating spatial skills. The congenitally blind are able to make sense of complex spatial arrays, and seem capable of drawing imagined transformations of perspectives (see Figure 4). The blind (both congenitally and late blind) subjects were able to produce good drawings of the cube, sphere, and cone. There were individual differences in drawing skills, with some subjects performing better than others. Drawing quality dropped somewhat when the subjects had to coordinate geometry and topology-that is, when they drew side views of the three objects in order (see Piaget \& Inhelder, 1948/1967). In addition, some subjects probably focused their attention on order information, and were not as concerned about exact form when drawing side views. Most subjects found drawing the array of three objects much easier from a bird's eye view than from the side views. The drawings in Figure 4 are representative of the congenitally blind's drawings of the shapes in isolation or from a bird's eye point of view; the drawing of the side view of the three objects was better than some of the congenitally blind's productions (but was certainly not the best).

The results of the present research suggest some optimism about the utility of drawing and pictures for the blind. The data are clearly inconsistent with theories that state that visual imagery is required for tactual perception of large, two-dimensional patterns (Lederman, Klatzky, Chataway, \& Summers, 1990). A number of differences between the Lederman et al. study and the present one could explain such radically different conclusions. Lederman et al. asked their subjects to identify twodimensional pictures of common objects. The process of naming pictures taps rather different cognitive skills than are used when one draws pictures of an object or an array of objects. Picture naming relies very heavily on categorical and classificatory skills, and depends on the nature of the drawings; some tangible drawings are identified more readily than others (Heller, 1989a). Furthermore, an individual may know what something is, yet remain unable to name it. Also, subjects in the present experiments were able to demonstrate their spatial understanding through drawing, and this may be a more sensitive measure of spatial cognition than verbal identification. It
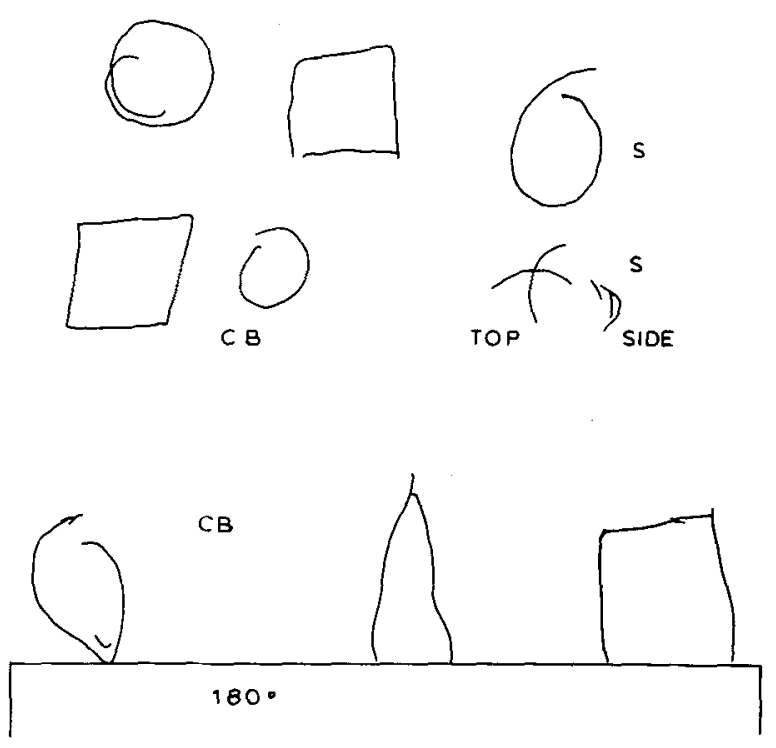

Figure 4. Bottom: a drawing of the $180^{\circ}$, side view perspective by a congenitally blind (CB) observer. Top: drawings of the top views of the cube and sphere by $C B$ subjects, and raised-line drawings (without sight; top and side views) of the sphere by two sighted (S) individuals.

should be remembered that the blind subjects in the present research had minimal exposure to haptic pictures, and very little experience in drawing (see Heller, 1989a). Despite this lack of familiarity with drawing, the subjects were able to place their tactile shapes accurately, with displacement errors that were slightly smaller than those of the sighted. It is difficult to predict how well congenitally blind subjects might have performed had they been given a history of increased exposure to drawing.

\section{REFERENCES}

Barber, P. O., \& Lederman, S. J. (1988). Encoding direction in manipulatory space and the role of visual experience. Joumal of Visual Impairment \& Blindness, 82, 99-106.

BORKE, H. (1975). Piaget's mountains revisited: Changes in the egocentric landscape. Developmental Psychology, 11, 240-243.

BowER, T. G. R. (1977). A primer of infant development. San Francisco: W. H. Freeman.

Davidson, P. W., ABbott, S., \& Gershenfeld, J. (1974). Influence of exploration time on haptic and visual matching of complex shape. Perception \& Psychophysics, 15, 539-543.

Dodd, A. G., HowarTh, C. I., \& CarTer, D. C. (1982). The mental maps of the blind: The role of previous visual experience. Joumal of Visual Impairment \& Blindness, 76, 5-12.

Heller, M. A. (1982). Visual and tactual texture perception: Intersensory cooperation. Perception \& Psychophysics, 31, 339-344.

Heller, M. A. (1983). Haptic dominance in form perception with blurred vision. Perception, 12, 607-613.

Heller, M. A. (1984). Active and passive touch: The influence of exploration time on form recognition. Journal of General Psychology, 110, 243-249.

Heller, M. A. (1985). Tactual perception of embossed Morse code and braille: The alliance of vision and touch. Perception, 14, 563-570.

Heller, M. A. (1989a). Picture and pattern perception in the sighted and blind: The advantage of the late blind. Perception, 18, 379-389. Heller, M. A. (1989b). Tactile memory in sighted and blind observers: 
The influence of orientation and rate of presentation. Perception, 18 , 121-133.

Heller, M. A. (1989c). Texture perception in sighted and blind observers. Perception \& Psychophysics, 45, 49-54.

Hollins, M., \& Kelley, E. K. (1988). Spatial updating in blind and sighted people. Perception \& Psychophysics, 43, 380-388.

JoNEs, B. (1975). Spatial perception in the blind. British Journal of Psychology, 66, 461-472.

JUURMAA, J. (1973). Transposition in mental spatial manipulation: A theoretical analysis. American Foundation for the Blind: Research Bulletin, 26, 87-134.

KENNEDY, J. M. (1982). Haptic pictures. In W. Schiff \& E. Foulke (Eds.), Tactual perception (pp. 305-333). Cambridge, U.K.: Cambridge University Press.

KenNedy, J. M. (1983). What can we learn about pictures from the blind? American Scientist, 71, 19-26.

Kennedy, J. M., Domander, R. (1984). Pictorial foreground/ background reversal reduces tactual recognition by blind subjects. Journal of Visual Impairment \& Blindness, 78, 215-216.

KENNeDY, J. M., \& Fox, N. (1977). Pictures to see and pictures to touch. In D. Perkins \& B. Leondar (Eds.), The arts and cognition (pp. 118-135). Baltimore: Johns Hopkins University Press.

KENNEDY, J. M., \& Gabias, P. (1985). Metaphoric devices in drawings of motion mean the same to the blind and the sighted. Perception, 14, 189-195.

Kinsbourne, M., \& Lempert, H. (1980). Human figure representation by blind children. Journal of General Psychology, 102, 33-37.

Lederman, S. J., Klatzky, R. L., Chataway, C., \& Summers, C. D. (1990). Visual mediation and the haptic recognition of two-dimensional pictures of common objects. Perception \& Psychophysics, 47, 54-64.

Lederman, S. J., Thorne, G., Jones, B. (1986). Perception of texture by vision and touch: Multidimensionality and intersensory integration. Journal of Experimental Psychology: Human Perception \& Performance, 12, 169-180.

LoOmIs, J. M. (1981). Tactile pattem perception. Perception, 10, 5-27.

MrLlar, S. (1975). Visual experience or translation rules? Drawing the human figure by blind and sighted children. Perception, 4, 363-371.

Millar, S. (1981). Self-referent and movement cues in coding spatial location by blind and sighted children. Perception, 10, 255-264.

Millar, S. (1988). Models of sensory deprivation: The nature/nurture dichotomy and spatial representation in the blind. Intemational Journal of Behavioral Development, 11, 69-87.

Morgan, M. J. (1977). Molyneux's question. New York: Cambridge University Press.

Piaget, J., Inhelder, B. (1967). The child's conception of space (F. J. Langdon \& J. L. Lanzer, Trans.). New York: Norton. (Original work published 1948).

Pick, H. L., JR. (1974). The visual coding of non-visual spatial information. In R. B. MacLeod \& H. L. Pick, Jr. (Eds.), Perception: Essays in honor of James J. Gibson (pp. 153-165). Ithaca, NY: Comell University Press.

Revesz, G. (1950). The psychology and art of the blind. London: Longmans Green.

Rueser, J. J., GUTH, M. A., \& Hill, E. W. (1986). Sensitivity to perspective structure while walking without vision. Perception, 15 , 173-188.

Rock, I., \& VictoR, J. (1964). Vision and touch: An experimentally created conflict between the two senses. Science, 143, 594-596.

Simpkins, K. E. (1979). The concept of space. Journal of Visual Impairment \& Blindness, 73, 81-85.

STRE LOW, E. R. (1985). What is needed for a theory of mobility: Direct perception and cognitive maps-lessons from the blind. Psychological Review, 92, 226-248.

WARREN, D. H. (1984). Blindness and early childhood development. New York: American Foundation for the Blind.

WELCH, R. B., \& WARREN, D. H. (1980). Immediate perceptual response to intersensory discrepancy. Psychological Bulletin, 88, 638-667.

WorCHEL, P. (1951). Space perception and orientation in the blind. Psychological Monographs, 65, 1-28.

\section{NOTES}

1. Average performance of the 3 RLF subjects in T-T bimanual shape matching (Experiment 2, mean number correct $=20$ ) was slightly better than that of the other congenitally blind and other blind individuals. Heller (1989c) recently reported similar performance for RLF and other early blind subjects in a texture perception task, and in picture identification (1989a). Furthermore, a number of RLF subjects were superior performers in a recent study of tactile memory where numbers were drawn on the skin (Heller, 1989b).

2. Sighted controls recruited in Winston-Salem and Toronto had superior educational backgrounds to the blind observers. Despite these educational differences, the blind often performed as well as, or better than, the sighted. It should be pointed out that the subjects with the least formal education, the late blind, have often outperformed other blind or sighted individuals (see Heller, 1989a).

3. Pointing (or a line of sight) is a visual index of the idea of a straight line (Piaget \& Inhelder, 1948/1967). Congenitally blind people have nonvisual methods of representing a straight line, which is just the shortest distance between two points. Diderot, in his Letters on the Blind, described a blind mathematician named Saunderson who used taut strings to represent straight lines (in Morgan, 1977, pp. 38 and 42).

4. Dot patterns in a $2 \times 2$ spatial matrix (braille patterns representing the letters A-J) were tapped out on the phalanges of the index and middle fingers of the 9 sighted, 9 congenitally blind, and 8 late blind subjects (one late blind subject was not familiar with braille). The patterns were presented by using the top of a pen to tap the index and middle fingers of the left hands of subjects, with about $1 \mathrm{sec}$ between taps. The braille code for the letters $A-J$ is represented by a $2 \times 2$ dot matrix, with the distal fingerprint skin of the index finger representing the top left dot; the second phalange represented the bottom left dot (corresponding to Braille Dots 1 and 2). The last two phalanges of the middle finger represented the right top and bottom dots (corresponding to Braille Dots 4 and 5). The entire braille code consists of a $2 \times 3$ dot matrix, with only the top 4 dots used for the letters A-J. Blind subjects relied on memory of the code, while the sighted had a drawing of the braille code and letter equivalents available during stimulation. Observers were required to name vocally the letter corresponding to the braille pattern that was passively experienced. This experiment permitted a tactile pattern perception comparison between the blind and sighted that was not contaminated by increased familiarity of the sighted with the stimuli. While the blind subjects were more familiar with braille, none had ever experienced the stimuli in the present manner. Blind subjects demonstrated their knowledge of braille by naming the dot positions for the braille code for these letters. Braille identification was similar for the three groups of subjects. Mean number correct, for the sighted, congenitally blind, and late blind, were $25.4,23.9$, and 20.9 , respectively. The effect of visual status was nonsignificant $[F(2,23)=1.2, p>.05]$. This experiment provides little support for the idea that visual imagery is necessary for tactile pattern recognition.

5. Successful anticipation of another perspective may be a higher level cognitive achievement than is universally found in the typical 10-11year-old sighted child. An informal assessment of this was undertaken by exposing 4 sighted 14-year-olds and a sighted 13-year-old to the present perspective task with full vision at all times (at the Ontario Science Centre). The subjects were asked to draw top and side views (with free vision and paper and pencil) from the various perspectives, and were then shown the five pictures, one at a time for perspective identification. The mean number of correct drawings was only 2.6 , with 1 subject obtaining a perfect score and the other 4 failing at all rotations from egocentric (top and front/side) points of view. The data from these 5 subjects are representative of several groups of children we have tested informally. Performance was better with identification, with a mean of 4.2 correct out of 5 . This suggests that drawing may sometimes increase the difficulty subjects have in considering all of their perceptual options. These sighted adolescents performed at a much lower level using sight and drawing than the congenitally blind subjects in the tactile perspectivedrawing task. Drawing perspectives probably accesses higher level cognitive/spatial skills in the sighted and blind. 